\title{
PD-1/PD-L1 expression in pancreatic cancer and its implication in novel therapies
}

\author{
Adrian Mucileanu ${ }^{1}$, Romeo Chira ${ }^{2}$, Petru Adrian Mircea ${ }^{2}$
}

1) Iuliu Hatieganu University of Medicine and Pharmacy, ClujNapoca, Romania

2) Gastroenterology Department, Medical Clinic No. 1, Iuliu Hatieganu University of Medicine and Pharmacy, Cluj-Napoca, Romania

DOI: $10.15386 / \mathrm{mpr}-2116$

Manuscript received: 20.03 .2021

Received in revised form: 11.05.2021

Accepted: 14.07.2021

Address for correspondence:

romeochira@yahoo.com

This work is licensed under a Creative Commons Attribution-NonCommercialNoDerivatives 4.0 International License

\begin{abstract}
Pancreatic cancer is the seventh leading cause of death in developed countries and it still has a poor prognosis despite intense research in the last 20 years. Immunotherapy is a relatively new strategy in cancer treatment. The aim of immunotherapy is to block the immunosuppressive effect of tumoral cells. The PD1/PD-L1 axis has an important role in the inhibition of effector $\mathrm{T}$ cells and the development of regulatory $\mathrm{T}$ cells (Tregs). Blocking these checkpoints, and also inhibitory signals, leads to apoptosis of Tregs and increased immune response of effector $T$ cells against tumoral antigens. Unfortunately, pancreatic cancer is generally considered to be a non-immunogenic tumor. Thus PD-1/PD-L1 inhibitors demonstrated poor results in pancreatic cancer, excepting some patients with MSI/dMMR (microsatellite instability/deficient mismatch repair). Furthermore, pancreatic cancer has a particular microenvironment with a strong desmoplastic reaction, increased interstitial fluid pressure, hypoxic conditions, and acidic extracellular $\mathrm{pH}$, which promote tumorigenesis and progression of the tumor. Mismatch repair deficiency (dMMR) is correlated with a high level of mutation-associated neoantigens, most recognized by immune cells which could predict a favorable response to anti-PD-1/ PD-L1 therapy. PD-1/PD-L1 molecules could be also found as soluble forms (sPD1, sPD-L1). These molecules have a potential role in the prognosis and treatment of pancreatic cancer.
\end{abstract}

Keywords: pancreatic neoplasma, PD-1, PD-L1, immunotherapy, immune checkpoint inhibitors

\section{Introduction}

Pancreatic cancer is the seventh leading cause of death in developed countries and represents $6.8 \%$ and $7.1 \%$ of all deaths caused by cancer among males and females, respectively. With a life expectancy of $8 \%$ at 5 years, the prognosis of this cancer has not improved over the past 20 years, and incidence and mortality rates are very similar [1].

Chemotherapy with or without radiotherapy and the molecular targeted therapy has poor results. Surgery remains the only potential curable treatment of pancreatic cancer but resection is possible only in $15 \%$ of cases [2].

With the development of immunooncology, increasing interest was given to immune checkpoint inhibitors as therapeutic targets but also as prognostic factors. Compared to other anticancer therapies, immunotherapy has a relatively low rate of complications [3]. Among immune checkpoints, a very promising therapeutic target is the programmed cell death protein 1 (PD-1) and the programmed cell death ligand (PD-L1) [4].

Unfortunately, pancreatic cancer is generally considered to be a nonimmunogenic tumor, due to the presence of immunosuppressive elements in the microenvironment, like regulatory $\mathrm{T}$ cells (Tregs), myeloid-derived suppressor cells (MDSC) and tumor-associated macrophages (TAM) [5].

However, clinical trials demonstrated better results of immunotherapy in some patients with high level microsatellite instability 
(MSI-H) tumors [6]. There is an increasing interest in soluble checkpoints and many studies are ongoing, trying to understand their role in cancer development and how they can be used as therapeutic targets.

The aim of this review is to present the implication of PD-1/PD-L1 checkpoint in pancreatic cancer and secondly to analyze, based on the available data, the therapeutic efficacy of the blockers of this checkpoint.

\section{PD1/PD-L1 checkpoint}

Programmed cell death-1 (PD-1, CD279) is a member of immunoglobulin superfamily and was identified for the first time in 1992 by Tasuku Honjo [6,7]. It is mainly expressed on $\mathrm{T}$ cells, but also on natural killer $\mathrm{T}$ cells, $\mathrm{B}$ cells, activated monocytes and dendritic cells [8].

The expression of PD- 1 on naive T cells is induced by activation of $\mathrm{T}$ cells, playing an important role in maintaining immune homeostasis [7]. Moreover, PD-1 is upregulated by PolyIC and cytokines produced by immune cells like IL-2, IL-4, IL-7, IL-10, IL-15, IL-21 TNF $\alpha$, IFN $\gamma$ and growth stem cell factor [4,9]. Voron et al. demonstrated that VEGF-A which is produced in the tumoral microenvironment increases the expression of PD1. Therefore antiangiogenic agents could have an inhibitory effect on PD-1 expression [10].

PD-1 has two ligands known as PD-L1 (CD 279) and PD-L2 (CD 273) [11].

PD-L1 is the most important ligand of PD-1 and is expressed by $\mathrm{T}$ cells, $\mathrm{B}$ cells, dendritic cells, macrophages and tumoral cells [8].

PD-L2 is mainly expressed by dendritic cells, macrophages, and B cells, but much less in tumoral cells [12].

It has been demonstrated in some cancers like ovarian cancer or melanoma that IFN gamma secreted by $\mathrm{T}$ cells or NK cells increase PD-L1 secretion at the surface of the tumoral cell and is associated with the progression of the disease $[12,13]$.

The PD1/PD-L1 axis has an important role in the inhibition of effector $\mathrm{T}$ cells and the development of regulatory $\mathrm{T}$ cells (Tregs) [8]. Regulatory $\mathrm{T}$ cells promote immune tolerance. They have important implications in controlling allergy, autoimmunity, inflammation, and tumors immunity $[14,15]$.

The PD1/PD-L1 checkpoint is mainly involved in the regulation of the late immune response in the peripheral tissue and less in the early immune response developed in lymph nodes, where the main player is the cytotoxic T-lymphocyte-associated antigen 4 CTLA-4 [16].

As opposed to chemotherapies and targeted therapies, which aim to directly destroy cancer cells, immune checkpoint-directed therapies bind lymphocyte ligands or receptors to enhance the lymphocyte activation and allow a cytotoxic antitumor immune response.
The tumor cells can avoid the host immune attack by promoting immunosuppression. A common way to promote immunosuppression is by activation of immune checkpoints. Blocking these checkpoints was seen as a potential strategy in the treatment of cancer (Figure 1). Therefore antibodies against receptors involved in immune checkpoints were developed, enhancing the immune response against tumor cells.

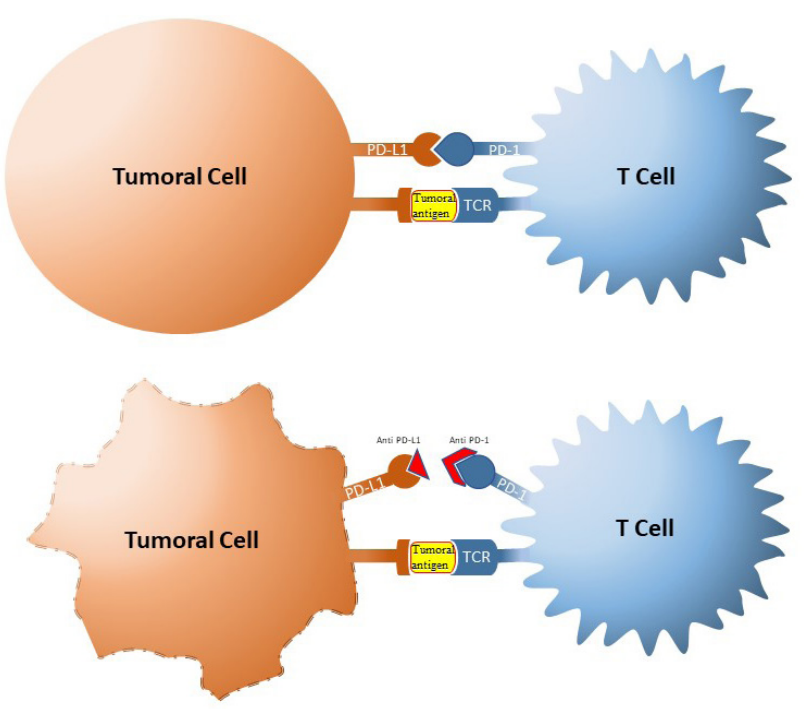

Figure 1. The mechanism of PD1/PD-L1 checkpoint blockade.

Blocking these checkpoints and also the inhibitory signals leads to apoptosis of Tregs and increased immune response of effector $\mathrm{T}$ cells against tumor antigens [17]. Tumor cells use this mechanism increasing the expression of PD-L1 which binds to PD-1, induce apoptosis or exhaustion of $\mathrm{T}$ cells and thus the tumor escapes immune surveillance [18].

Antibodies blocking the PD-1/L1 inhibitory axis can unleash activated tumor-reactive $\mathrm{T}$ cells to proliferate and attack tumor cells and they have been shown in clinical trials to induce durable antitumor responses of $10-50 \%$ of cases, in different types of tumors [19]. Pembrolizumab was the first blocking agent of PD-1/PD-L1 checkpoint approved in 2014 by the Food and Drug Administration (FDA) in the treatment of advanced malignant melanoma [20].

The PD-1 inhibitors, pembrolizumab and nivolumab (anti-PD-1) were recently approved by FDA in the treatment of many types of cancers, including non-small cell lung cancer, urothelial carcinoma, renal cell carcinoma, gastrointestinal carcinomas, and metastatic melanoma [2124] and since 2018 cemiplimab for cutaneous squamous cell carcinoma [25]. The PD-L1 inhibitor Atezolizumab 
has the FDA approval for the treatment of non-small-cell lung carcinoma, breast and urothelial carcinoma [26-28].

The tumoral expression of PD-L1, assessed by immunohistochemistry (IHC) staining, has been identified as a biomarker associated with a higher chance of tumor response in patients treated with anti-PD-L1 antibodies and better overall survival in multiple tumor types.

The need for biomarkers of response to immunotherapeutic agents relies on the great variability of responses to immune checkpoint inhibitors (ICIs) and, therefore, the difficulties of patient selection for appropriateness of care. One of the most widely used biomarkers to predict response to anti-PD-1 is the expression of PD-L1 on tumor cells detected by immunohistochemistry (IHC).

Expression of PD-L1 in the tumor may be underestimated, when it is evaluated by immunohistochemistry, because of different available PD-L1 antibody clones with different characteristics [29]. Another source of error in the evaluation of the PDL1 expression using a biopsy sample is the intratumoral heterogeneity or dissimilar expression of PD-L1 between some primary tumors and metastasis [30,31].

\section{PD1/PD-L1 expression in pancreatic cancer}

PD-L1 is expressed mainly in tumoral cells and rarely in normal cells. The PD1/PD-L1 checkpoint has an immunosuppressive role and this could explain why the upregulation of $\mathrm{PD} 1 / \mathrm{PD}-\mathrm{L} 1$ promoted by tumoral cells is associated with a bad prognosis. These findings suggest that PD1/PD-L1 checkpoint inhibition could enhance endogenous antitumoral immunity [32-35].

Loos et al. investigated the expression of the B7 family in pancreatic cancer using reverse transcription PCR (RT-PCR) and concluded that only PD-L1 had a prognostic value. Therefore the postoperative median survival of patients with high PD-L1 expression was only 10 months compared with those with low PD-L1 expression, who had a median survival of 24 months [36]. In another study on 453 patients with pancreatic cancer the expression of PD-L1 mRNA was analyzed and the samples positive for PD-L1 displayed evidence of lymphocyte exhaustion. These patients had shorter disease-free survival and overall survival [37].

A meta-analysis demonstrated that high expression of PD-L1 in pancreatic cancer was associated with positive $\mathrm{N}$ stage, advanced $\mathrm{T}$ stage and low differentiation, but not significant with $\mathrm{M}$ stage [38].

In pancreatic cancer, PD-1/PD-L1 inhibitors demonstrated no therapeutic effects, excepting those patients with MSI/dMMR [39]. Currently, there are some trials that determine the efficacy of PD-1/PD-L1 blockers in combination with chemotherapy, viruses, vaccines, radiotherapy (NCT03723915, NCT02648282,
NCT02546531) [40-42]. A preclinical study in a mouse model of pancreatic cancer, demonstrated a better antitumoral effect when anti-PD1/PD-L1 was combined with gemcitabine [34]. A combination of anti-PD-1 therapy and GVAX (cancer vaccine) demonstrated an increased overall survival an also an increased infiltration of (IFN)gamma-producing CD8+ T cells [43].

But the mechanism of PD-1/PD-L1 pathway is not fully understood and further studies remain to explain for example why in some cancers like breast cancer and Merkel cell carcinoma a high expression of PD-L1 seems to have a positive prognosis $[44,45]$.

When evaluating the expression of PD-L1, the chosen method is important. In a meta-analysis, Gao et al demonstrated that immunohistochemistry (IHC) in pancreatic cancer had a higher rate of detection of PDL1 compared with polymerase chain reaction (PCR) $(54.5 \%$ vs. $32.2 \%)$ [46]. Another study on non-small cell lung cancer revealed a good agreement between PD-L1 mRNA levels measured by RT-qPCR and IHC [47]. Also, the PD-L1 protein expression by IHC analysis has been the main predictive biomarker explored for a response to immunotherapy.

Several studies reported a poor prognosis in patients with increased expression of PD-L1. In a study conducted by Tessier-Cloutier et al. patients with resected pancreatic tumors with high expression of PD-L1 $(>10 \%)$ on immunohistochemistry, were associated with poor diseasespecific survival [48]. Similar results were reported by Yamaki et al. in a small study using immunostaining with fluorescent phosphor-integrated dot (PID) nanoparticles [49]. In another study it was demonstrated that patients with pancreatic cancer with intense CD8+ TILS and PD-1+ TILs (tumor-infiltrating lymphocytes) infiltrate had a better prognosis [50].

\section{Pancreatic cancer microenvironment}

The pancreatic tumor microenvironment includes cellular components (fibroblasts, stellate cells, endothelial cells, nerve cells, immune cells) and non-cellular components (glycoproteins, glycosaminoglycans, proteoglycans, enzymes, growth factors). These components seem to have a role in the prognosis and efficacy of some therapies [51].

From the immune perspective, the pancreatic tumor microenvironment is different from many solid tumors. The resistance of pancreatic cancer to chemotherapy or immunotherapy is mainly due to the particular microenvironment of this tumor.

This microenvironment is lacking effector $\mathrm{T}$ cells infiltration and is rich in immunosuppressive cells like Tregs or myeloid-derived suppressor cell (MDSC) [52]. Moreover, pancreatic cancer develops a strong desmoplastic reaction which can act as a biophysical barrier for CD8+ $\mathrm{T}$ cells infiltration but also for therapeutic 
agents [53]. Besides, increased interstitial fluid pressure, hypoxic conditions, and acidic extracellular $\mathrm{pH}$ promote tumorigenesis and progression of the tumor [54].

A study on KPC mice, which is a model that expresses mutant Kras and p53 and develop spontaneous pancreatic tumors, revealed leukocyte invasion during disease progression. Nevertheless, these leukocytes were represented mainly by tumor-associated macrophages, myeloid-derived suppressor cells (MDSC) and regulatory $\mathrm{T}$ cells that have an immunosuppressive role, while effector $\mathrm{T}$ cells were scarce [55]. This pattern suggests immunosuppressive status during the development of pancreatic cancer.

Cancer-associated fibroblasts (CAF) induce downregulation of antitumoral cells and it was demonstrated that targeting CAF is associated with a better response to anti-PD-L1 therapy [56,57]. Also, CAF express fibroblast activation protein- $\alpha$ (FAP) and in a study on KPC mice, it was demonstrated that depletion of FAP + stromal cells improved the anti-PD-L1 therapy [56].

All of these aspects of pancreatic cancer microenvironment lead to highly immunosuppressive microenvironment, and this is one of the reasons why immunotherapy has low efficacy in pancreatic adenocarcinoma.

Another reason for the low effect of immunotherapy in pancreatic cancer is the poor immunogenicity of this type of tumor. The lack of immunogenicity of pancreatic tumoral microenvironment is due to poor antigenicity [58]. Pancreatic cancer contains an average of 33 to 66 somatic mutations, fewer compared with other cancers. One explanation could be the lack of replication of ductal cells of the pancreas, unlike the epithelial cells of the colon [59].

\section{Biomarkers for PD-L1 system in serum/ plasma \\ In addition to membranous ligands and receptors} of the immune regulation system, special attention has been given to soluble variants. Soluble forms of PD-1/ PD-L1 (sPD-1/PD-L1) were identified for the first time in autoimmune disorders [60]. These soluble immune checkpoints are found in the plasma and originate from the expression of mRNA or by cleavage of membranous proteins [61]. sPD-L1 could be produced and released by tumoral cells and activated mature dendritic cells [62]. The SPD-L1 is detectable in the serum of healthy humans and its level increases with age. Thus it was demonstrated that the level of sPD-L1 was lowest in children (3-10 years old) whereas adults (51-70 years old) had the highest level [61].

Because the evaluation of PD-L1 status of a tumor requires a biopsy which is an invasive procedure, and considering the heterogeneity of some tumors like pancreatic cancer, soluble checkpoints have been regarded as potential surrogates of PD-L1 expression.

SPD1/PD-L1 have an important role in immune regulation, being associated with the prognosis of cancer and are also potential therapeutic targets.

In vivo, soluble ligands of the immune regulation system could interact with their membrane-bound receptors. Also, soluble receptors of the checkpoint system could bind to their membrane-bound ligands. sPD-1 could block the interaction between PD/L1/CD80, PD-L1/PD-1, and PD-L2/PD-1 [63]. Therefore mPD-L1 or mPD-L2 could bind to SPD-1, instead of mPD-1 expressed by $\mathrm{T}$ cells. As a consequence of this binding, $\mathrm{mPD}-1$ at the level of $\mathrm{T}$ cell remains unbound, $\mathrm{T}$ cell is not inactivated and immunosuppression is avoided [61]. Regarding SPD-L1, binding to PD-1, and consequently generation of an inhibitory signal is under debate [64].

High levels of sPD-L1 have been reported to be associated with poor prognosis in some solid cancers [65]. Contradictory results were reported in a study conducted by Zheng et al. They found that high levels of SPD-L1 in patients with gastric cancer are correlated with a high grade of differentiation, absence of lymph nodes and better prognosis [66]. The reason why high levels of sPD-L1 are associated with bad prognosis in some cancers and good prognosis in others is still unknown.

The correlation between sPD-1/sPD-L1 and overall survival was contradictory in some studies (Table I). Bian et al. found a positive correlation between sPD1/PD-L1 and overall survival in patients with locally advanced or metastatic pancreatic cancer. In this study for the detection of SPD-1 and SPD-L1 plasma was preferred instead of serum because the levels of soluble markers in plasma were 10 times higher than in serum [67]. This could explain the lack of correlation between soluble PD-1/PD-L1 and overall survival in another study conducted by Kruger et al. In this study the serum levels of sPD-1/PD-L1 of patients with advanced pancreatic cancer were evaluated. The tumoral expression of PD-L1 was not correlated with the level of sPD-L1. This observation could suggest the different origins of PD-L1. Instead, CRP levels were found to correlate with overall survival (OS) [68]. This observation suggests that sPD-L1 could be a marker of systemic inflammation in advanced pancreatic cancer.

In a study on mice, it has been demonstrated that expression of the sPD-1 blocks the interaction between PD-1 and PD-L1 and consequently reduces the tumor inhibitory effect on $\mathrm{T}$ cells and enhances cytotoxicity [70].

The role of sPD-1/PD-L1 is not fully understood, and further studies are needed to reveal the mechanisms of these molecules and use them as a target in cancer therapy. 
Table I. Correlation of serum levels of SPD-1 and SPD-L1 with overall survival in pancreatic cancer.

\begin{tabular}{|c|c|c|c|c|c|c|}
\hline \multirow[t]{2}{*}{ Study } & \multirow{2}{*}{$\begin{array}{l}\text { Blood } \\
\text { samples }\end{array}$} & \multicolumn{2}{|c|}{$\begin{array}{c}\text { Correlation with overall } \\
\text { survival (OS) }\end{array}$} & \multirow{2}{*}{$\begin{array}{l}\text { Follow up (median) } \\
\text { (months) }\end{array}$} & \multirow[t]{2}{*}{ Overall survival (OS)(months) } & \multirow{2}{*}{$\begin{array}{l}\text { Cohort study } \\
\text { (Reference) }\end{array}$} \\
\hline & & sPD-1 & sPD-L1 & & & \\
\hline 1 & 41 & No correlation & No correlation & $24.7(95 \% \mathrm{CI}, 19.6-30.0)$ & $\begin{array}{l}\text { 9.53(95\%CI, 5.06-13.99) for low } \\
\text { sPDl1/sPD-1(20) } \\
\text { 11.93(95\%CI, 6.41-17.44) for high } \\
\text { sPD-L1/sPD-1(21) }\end{array}$ & Prospective [68] \\
\hline 2 & 59 & $\begin{array}{l}\text { Negative } \\
\text { correlation }\end{array}$ & $\begin{array}{l}\text { Negative } \\
\text { correlation }\end{array}$ & - & $6.9(95 \% \mathrm{CI}, 4.4-10.19)$ & Prospective [67] \\
\hline 3 & 60 & $\begin{array}{l}\text { Negative } \\
\text { correlation }\end{array}$ & No correlation & 11.4 & $10.3(95 \% \mathrm{CI}, 8.5-12.1)$ & Prospective [69] \\
\hline
\end{tabular}

Mismatch repair deficiency, microsatellite instability, and tumor mutational burden

Another aspect correlated with the anti-PD-1/PDL1 response is the status of mismatch repair (MMR) system and microsatellite instability (MSI). The malfunctioning of the MMR system, known as mismatch repair deficiency (dMMR) leads to a high burden of DNA mutations which can lead to the presence of high levels of mutationassociated neoantigens, most recognized by immune cells.

Kim et al. reported in MLH1/MSH2 negative tumors, a PD-L1 expression of $38.9 \%$ and in proficient MMR (pMMR) a PD-L1 expression of only $15.2 \%$ [71]. Le DT et al. using exome sequencing, found in dMMR an average of 1782 somatic mutations per tumor and 578 potential neoantigens while in pMMR tumors found only 73 mutations and 21 neoantigens. Somatic mutations and neoantigens are correlated with a better response to antiPD-1/PD-L1 therapy [39].

It was demonstrated that tumors with deficient mismatch repair (dMMR) and a high level of MSI (MSI-H) have an increased infiltration of CD8+ TILs and this could explain the better and more durable response to immune checkpoint blockade, particularly to anti-PD1/PD-L1 therapy [6]. Therefore evaluation of MMR and MSI status could identify responders to PD-1/PD-L1 inhibitors.

In 2017, pembrolizumab was granted accelerated FDA approval for patients with unresectable or metastatic MSI-H or dMMR solid tumors that have progressed following prior treatment and who have no satisfactory alternative treatment options. This was the first time that a biomarker defined the indication for treatment irrespective of tumor location or histology, as a tumor-agnostic treatment.

The NCCN guidelines published in 2021 recommend the use of pembrolizumab as first line therapy in low performance status patients, with MSI-H or dMMR metastatic pancreatic tumors. Furthermore, pembrolizumab could be used as subsequent therapy in patients with MSI-H or dMMR metastatic or locally advanced pancreatic tumors, regardless performance status [72].

The Keynote 158 study included 22 patients with previously treated unresectable or metastatic MSI-H/ dMMR pancreatic cancer. It reported an ORR of $18.2 \%$ (95\% CI 5.2\%-40.3\%), a median PFS of 2.1 months (95\% CI 1.9-3.4 months), and a median OS of 4 months [73].

In clinical practice, testing the MMR status could be taken into consideration regardless of tumor origin, for the administration of immunotherapy to patients with dMMR or MSI-H tumors. The National Comprehensive Cancer Network (NCCN) guidelines recommend testing of MSI or MMR status, on available tumoral tissue, in locally advanced and metastatic pancreatic adenocarcinoma. Therefore in patients with pancreatic adenocarcinoma with MSI-H or dMMR, pembrolizumab should be considered as second-line therapy in locally advanced or metastatic disease $[72,74]$. Unfortunately, pancreatic adenocarcinoma is very rarely associated with MSI or dMMR, but more studies are needed to establish accurately the real prevalence of MSI and dMMR in pancreatic cancer. Hu et al. found that only $0.8 \%(7 / 833)$ of patients with pancreatic cancer had dMMR and all of these patients had Lynch syndrome [75]. Also, a rate of $22 \%$ of MSI/dMMR was reported in pancreatic cancer, but these discordant results could be explained by using non-standardized methods of MSI/dMMR detection [76].

In addition to MMR and MSI, tumor mutational burden (TMB) is a promising predictor for the efficacy of anti-PD-1/PD-L1 therapy. TMB represents the total number of mutations per coding area of the tumoral genome. In a study conducted on 1662 patients of different histologies treated with anti CTLA4 or anti-PD-1 therapies, Samstein et al. reported that higher TMB was associated with better overall survival. Also, TMB seems to be a more accurate predictive marker of efficacy of immune checkpoint blockade, compared with dMMR/MSI-H or PD-1/PD-L1 expression [77]. Studies reported that most patients with MSI-H had high levels of TMB, but not all patients with high TMB levels expressed dMMR/MSI-H [78]. Hence 
the evaluation of the status of TMB could bring a benefit in patients with cancer, considering that TMB is a good predictive marker for the response to immune checkpoint blockade and next-generation sequencing is becoming more accessible in clinical practice [79].

In a large cohort study of 9887 samples from 35 distinct tumor types, PD-L1 and TMB were reported to be relatively independent predictive markers and both could bring data about the probability of response to immune checkpoint inhibition [80]. Therefore the evaluation of TMB in addition to PD-L1 expression, may be a solution for a better selection of patients that could respond to immune checkpoint blockade.

BRCA 1 and BRCA 2 are associated with an increased risk mainly of ovarian and breast cancer [81], but also pancreatic cancer [82]. In patients with pancreatic cancer, the prevalence of BRCA mutations is 4 to $7 \%$ [83]. Recently, in the POLO trial, it was demonstrated that patients with pancreatic cancer which bear mutations of BRCA1 or BRCA2 are sensitive to poly (adenosine diphosphate-ribose) polymerase (PARP) inhibitors like olaparib [83].

\section{Future perspectives}

Immunotherapy is a relatively new strategy in cancer treatment. Despite these recent breakthroughs in developing checkpoint inhibitors to treat advanced melanoma and other cancers, a significant number of patients do not respond to PD-1/PD-L1 blockade, or experience disease progression after an initial response. Therapeutic failure could be explained by a lack of sufficient immune activation against cancer or an overwhelming suppressive tumor microenvironment that is hard to overcome. As it was mentioned above, immunotherapy alone has no efficacy in pancreatic cancer, excepting patients with MSI-H/dMMR tumors. Some results were stated when immunotherapy was combined with other therapies. This could be a key to exploit the benefits of immunotherapy and further research should be conducted on this. Also, chemotherapy and radiotherapy induce tumoral cell death and further release of tumoral antigens which leads to $\mathrm{T}$ cell activation in the tumoral microenvironment where checkpoint inhibitors could maintain intratumoral immunogenicity [84].

Studies on soluble PD-1/PD-L1 are scarce and further studies are needed to better understand their roles and if these markers can be used as target therapies or set as an indication for specific therapy.

Many studies are developing, trying to target the tumoral microenvironment, but for now, they have disappointing results [85].

According to the last studies, microbiota seems to be involved in immunologic development and carcinogenesis of gastrointestinal cancers including pancreatic cancer $[86,87]$. Therefore, modulation of the microbiota is a potential strategy to enhance the efficacy of immunotherapy $[88,89]$. A good reason in favor of further development of immunotherapy is the relatively low rate of complications compared with other cancer treatments $[3,90]$.

Nevertheless, until an effective treatment for pancreatic cancer will be available, early diagnosis is the best strategy. Screening for pancreatic cancer is difficult but at least high-risk patients should be regularly evaluated.

\section{Conclusions}

Pancreatic cancer is one of the most lethal cancers and at the same time one of the most resistant to chemotherapy and immunotherapy, especially due to the particular tumoral microenvironment. Many trials evaluated the efficacy of immunotherapy in pancreatic cancer, especially PD-1/PD-L1 inhibitors but some real benefits were proven only in patients with MSI or dMMR. Unfortunately, pancreatic adenocarcinoma is very rarely associated with MSI or dMMR, and this association could be in the context of Lynch syndrome.

PD-L1 protein expression by IHC analysis has been the main predictive biomarker explored for a response to immunotherapy. Comparative studies of PD-L1 detection methods and antibodies will be important for guiding the use of immunotherapy for patient care and the development of immunotherapy biomarker guidelines.

In order to increase its effectiveness, immunotherapy was associated in some studies with chemotherapy, radiotherapy, viruses or vaccines, but the results are still poor. Also, special attention has been given to soluble variants of PD-1/PD-L1 and the immunomodulatory role of intestinal microbiota.

\section{References}

1. Siegel RL, Miller KD, Jemal A. Cancer statistics, 2018. CA Cancer J Clin 2018; 68: 7-30.

2. Cress RD, Yin D, Clarke L, Bold R, Holly EA. Survival among patients with adenocarcinoma of the pancreas: a population-based study (United States). Cancer Causes Control. 2006;17:403-409.

3. Carretero-González A, Lora D, Ghanem I, Otero I, López F, Castellano D, et al. Comparative safety analysis of immunotherapy combined with chemotherapy versus monotherapy in solid tumors: a meta-analysis of randomized clinical trials. Oncotarget. 2019;10:3294-3301.

4. Salmaninejad A, Valilou SF, Shabgah AG, Aslani S, Alimardani M, Pasdar A, et al. PD-1/PD-L1 pathway: Basic biology and role in cancer immunotherapy. J Cell Physiol. 2019;234:16824-16837.

5. Feng M, Xiong G, Cao Z, Yang G, Zheng S, Song X, et al. PD-1/PD-L1 and immunotherapy for pancreatic cancer. Cancer Lett. 2017;407:57-65.

6. Le DT, Uram JN, Wang H, Bartlett BR, Kemberling H, Eyring AD, et al. PD-1 Blockade in Tumors with Mismatch- 
Repair Deficiency. N Engl J Med. 2015;372:2509-2520.

7. Ishida Y, Agata Y, Shibahara K, Honjo T. Induced expression of PD-1, a novel member of the immunoglobulin gene superfamily, upon programmed cell death. EMBO J. 1992;11:3887-3895.

8. Keir ME, Butte MJ, Freeman GJ, Sharpe AH. PD-1 and its ligands in tolerance and immunity. Annu Rev Immunol. 2008;26:677-704.

9. Kinter AL, Godbout EJ, McNally JP, Sereti I, Roby GA, O'Shea MA, et al. The common gamma-chain cytokines IL-2, IL-7, IL-15, and IL-21 induce the expression of programmed death-1 and its ligands. J Immunol. 2008;181:6738-6746.

10. Voron T, Colussi O, Marcheteau E, Pernot S, Nizard $\mathrm{M}$, Pointet AL, et al. VEGF-A modulates expression of inhibitory checkpoints on CD8+ T cells in tumors. J Exp Med. 2015;212:139-148.

11. Freeman GJ, Long AJ, Iwai Y, Bourque K, Chernova $\mathrm{T}$, Nishimura $\mathrm{H}$, et al. Engagement of the PD-1 immunoinhibitory receptor by a novel B7 family member leads to negative regulation of lymphocyte activation. J Exp Med. 2000;192:1027-1034.

12. Abiko $\mathrm{K}$, Matsumura $\mathrm{N}$, Hamanishi J, Horikawa $\mathrm{N}$, Murakami R, Yamaguchi K, et al. IFN- $\gamma$ from lymphocytes induces PD-L1 expression and promotes progression of ovarian cancer. Br J Cancer. 2015;112:1501-1509.

13. Garcia-Diaz A, Shin DS, Moreno BH, Saco J, Escuin-Ordinas $\mathrm{H}$, Rodriguez GA, et al. Interferon Receptor Signaling Pathways Regulating PD-L1 and PD-L2 Expression. Cell Rep. 2017;19:1189-1201.

14. Panduro M, Benoist C, Mathis D. Tissue Tregs. Annu Rev Immunol. 2016;34:609-633.

15. Zhao H, Liao X, Kang Y. Tregs: Where We Are and What Comes Next? Front Immunol. 2017;8:1578.

16. Seidel JA, Otsuka A, Kabashima K. Anti-PD-1 and AntiCTLA-4 Therapies in Cancer: Mechanisms of Action, Efficacy, and Limitations. Front Oncol. 2018;8:86.

17. Leach DR, Krummel MF, Allison JP. Enhancement of antitumor immunity by CTLA-4 blockade. Science. 1996;271:1734-1736.

18. Sanmamed MF, Chen L. Inducible expression of B7-H1 (PDL1) and its selective role in tumor site immune modulation. Cancer J. 2014;20:256-261.

19. Larkin J, Chiarion-Sileni V, Gonzalez R, Grob JJ, Cowey $\mathrm{CL}$, Lao CD, et al. Combined Nivolumab and Ipilimumab or Monotherapy in Untreated Melanoma. N Engl J Med. 2015;373:23-34

20. Chuk MK, Chang JT, Theoret MR, Sampene E, He K, Weis SL, et al. FDA Approval Summary: Accelerated Approval of Pembrolizumab for Second-Line Treatment of Metastatic Melanoma. Clin Cancer Res. 2017;23:5666-5670.

21. Larkin J, Minor D, D'Angelo S, Neyns B, Smylie M, Miller WH Jr, et al. Overall Survival in Patients With Advanced Melanoma Who Received Nivolumab Versus Investigator's Choice Chemotherapy in CheckMate 037: A Randomized, Controlled, Open-Label Phase III Trial. J Clin Oncol. 2018;36:383-390.
22. Motzer RJ, Tannir NM, McDermott DF, Arén Frontera O, Melichar B, Choueiri TK, et al. Nivolumab plus Ipilimumab versus Sunitinib in Advanced Renal-Cell Carcinoma. N Engl J Med. 2018;378:1277-1290.

23. Bellmunt J, de Wit R, Vaughn DJ, Fradet Y, Lee JL, Fong L, et al. Pembrolizumab as Second-Line Therapy for Advanced Urothelial Carcinoma. N Engl J Med. 2017;376:1015-1026.

24. Reck M, Rodríguez-Abreu D, Robinson AG, Hui R, Csőszi T, Fülöp A, et al. Pembrolizumab versus Chemotherapy for PD-L1-Positive Non-Small-Cell Lung Cancer. N Engl J Med. 2016;375:1823-1833.

25. U.S. Food and Drug Administration. FDA D.I.S.C.O.: FDA approval of cemiplimab-rwlc for cutaneous squamous cell carcinoma 2018. Available from: https://www.fda.gov/ drugs/resources-information-approved-drugs/fda-discofda-approval-cemiplimab-rwlc-cutaneous-squamous-cellcarcinoma.

26. Powles T, Durán I, van der Heijden MS, Loriot Y, Vogelzang NJ, De Giorgi U, et al. Atezolizumab versus chemotherapy in patients with platinum-treated locally advanced or metastatic urothelial carcinoma (IMvigor211): a multicentre, open-label, phase 3 randomised controlled trial. Lancet. 2018;391:748-757.

27. Schmid P, Adams S, Rugo HS, Schneeweiss A, Barrios $\mathrm{CH}$, Iwata $\mathrm{H}$, et al. Atezolizumab and Nab-Paclitaxel in Advanced Triple-Negative Breast Cancer. N Engl J Med. 2018;379:2108-2121.

28. Socinski MA, Jotte RM, Cappuzzo F, Orlandi F, Stroyakovskiy D, Nogami N, et al. Atezolizumab for FirstLine Treatment of Metastatic Nonsquamous NSCLC. N Engl J Med. 2018;378:2288-2301.

29. Parra ER, Villalobos P, Mino B, Rodriguez-Canales J. Comparison of Different Antibody Clones for Immunohistochemistry Detection of Programmed Cell Death Ligand 1 (PD-L1) on Non-Small Cell Lung Carcinoma. Appl Immunohistochem Mol Morphol. 2018;26:83-93.

30. Nakamura S, Hayashi K, Imaoka Y, Kitamura Y, Akazawa Y, Tabata $\mathrm{K}$, et al. Intratumoral heterogeneity of programmed cell death ligand-1 expression is common in lung cancer. PLoS One. 2017;12:e0186192.

31. Li M, Li A, Zhou S, Xu Y, Xiao Y, Bi R, et al. Heterogeneity of PD-L1 expression in primary tumors and paired lymph node metastases of triple negative breast cancer. BMC Cancer. 2018;18:4.

32. Brahmer JR, Tykodi SS, Chow LQ, Hwu WJ, Topalian SL, Hwu P, et al. Safety and activity of anti-PD-L1 antibody in patients with advanced cancer. N Engl J Med. 2012;366:24552465.

33. Dong H, Strome SE, Salomao DR, Tamura H, Hirano F, Flies DB, et al. Tumor-associated B7-H1 promotes T-cell apoptosis: a potential mechanism of immune evasion. Nat Med. 2002;8:793-800.

34. Nomi T, Sho M, Akahori T, Hamada K, Kubo A, Kanehiro $\mathrm{H}$, et al. Clinical significance and therapeutic potential of the programmed death-1 ligand/programmed death-1 pathway in human pancreatic cancer. Clin Cancer Res. 2007;13:21512157. 
35. Wang Q, Liu F, Liu L. Prognostic significance of PDL1 in solid tumor: An updated meta-analysis. Medicine (Baltimore). 2017;96:e6369.

36. Loos M, Giese NA, Kleeff J, Giese T, Gaida MM, Bergmann $\mathrm{F}$, et al. Clinical significance and regulation of the costimulatory molecule B7-H1 in pancreatic cancer. Cancer Lett. 2008;268:98-109.

37. Birnbaum DJ, Finetti P, Lopresti A, Gilabert M, Poizat F, Turrini $\mathrm{O}$, et al. Prognostic value of PDL1 expression in pancreatic cancer. Oncotarget. 2016;7:71198-71210.

38. Hu Y, Chen W, Yan Z, Ma J, Zhu F, Huo J. Prognostic value of PD-L1 expression in patients with pancreatic cancer: A PRISMA-compliant meta-analysis. Medicine (Baltimore). 2019;98:e14006.

39. Le DT, Durham JN, Smith KN, Wang H, Bartlett BR, Aulakh LK, et al. Mismatch repair deficiency predicts response of solid tumors to PD-1 blockade. Science. 2017;357:409-413.

40. Pimentel M, Morales W, Rezaie A, Marsh E, Lembo A, Mirocha J, et al. Development and validation of a biomarker for diarrhea-predominant irritable bowel syndrome in human subjects. PLoS One. 2015;10:e0126438.

41. Hauser G, Tkalcic M, Pletikosic S, Grabar N, Stimac D. Erythrocyte sedimentation rate - possible role in determining the existence of the low grade inflammation in Irritable Bowel Syndrome patients. Med Hypotheses. 2012;78:818-820.

42. McKernan DP, Gaszner G, Quigley EM, Cryan JF, Dinan TG. Altered peripheral toll-like receptor responses in the irritable bowel syndrome. Aliment Pharmacol Ther. 2011;33:10451052.

43. Soares KC, Rucki AA, Wu AA, Olino K, Xiao Q, Chai Y, et al. PD-1/PD-L1 blockade together with vaccine therapy facilitates effector T-cell infiltration into pancreatic tumors. J Immunother. 2015;38:1-11.

44. Schalper KA, Velcheti V, Carvajal D, Wimberly H, Brown $\mathrm{J}$, Pusztai L, et al. In situ tumor PD-L1 mRNA expression is associated with increased TILs and better outcome in breast carcinomas. Clin Cancer Res. 2014;20:2773-2782.

45. Lipson EJ, Vincent JG, Loyo M, Kagohara LT, Luber BS, Wang H, et al. PD-L1 expression in the Merkel cell carcinoma microenvironment: association with inflammation, Merkel cell polyomavirus and overall survival. Cancer Immunol Res. 2013;1:54-63.

46. Gao HL, Liu L, Qi ZH, Xu HX, Wang WQ, Wu CT, et al. The clinicopathological and prognostic significance of PD-L1 expression in pancreatic cancer: A meta-analysis. Hepatobiliary Pancreat Dis Int. 2018;17:95-100.

47. Erber R, Stöhr R, Herlein S, Giedl C, Rieker RJ, Fuchs F, et al. Comparison of PD-L1 mRNA Expression Measured with the CheckPoint Typer ${ }^{\circledR}$ Assay with PD-L1 Protein Expression Assessed with Immunohistochemistry in Non-small Cell Lung Cancer. Anticancer Res. 2017;37:6771-6778.

48. Tessier-Cloutier B, Kalloger SE, Al-Kandari M, Milne K, Gao D, Nelson BH, et al. Programmed cell death ligand 1 cut-point is associated with reduced disease specific survival in resected pancreatic ductal adenocarcinoma. BMC Cancer. 2017; 17:618.

49. Yamaki S, Yanagimoto H, Tsuta K, Ryota H, Kon M. PD-
L1 expression in pancreatic ductal adenocarcinoma is a poor prognostic factor in patients with high $\mathrm{CD}^{+}$tumor-infiltrating lymphocytes: highly sensitive detection using phosphorintegrated dot staining. Int J Clin Oncol. 2017;22:726-733.

50. Fukunaga A, Miyamoto M, Cho Y, Murakami S, Kawarada Y, Oshikiri T, et al. $\mathrm{CD}^{+}$tumor-infiltrating lymphocytes together with $\mathrm{CD}^{+}$tumor-infiltrating lymphocytes and dendritic cells improve the prognosis of patients with pancreatic adenocarcinoma. Pancreas. 2004;28:e26-e31.

51. Rucki AA, Zheng L. Pancreatic cancer stroma: understanding biology leads to new therapeutic strategies. World J Gastroenterol. 2014;20:2237-2246.

52. Fridman WH, Pagès F, Sautès-Fridman C, Galon J. The immune contexture in human tumours: impact on clinical outcome. Nat Rev Cancer. 2012;12:298-306.

53. Ene-Obong A, Clear AJ, Watt J, Wang J, Fatah R, Riches JC, et al. Activated pancreatic stellate cells sequester CD8+ T cells to reduce their infiltration of the juxtatumoral compartment of pancreatic ductal adenocarcinoma. Gastroenterology. 2013;145:1121-1132.

54. Turley SJ, Cremasco V, Astarita JL. Immunological hallmarks of stromal cells in the tumour microenvironment. Nat Rev Immunol. 2015;15:669-682.

55. Clark CE, Hingorani SR, Mick R, Combs C, Tuveson DA, Vonderheide RH. Dynamics of the immune reaction to pancreatic cancer from inception to invasion. Cancer Res. 2007;67:9518-9527.

56. Feig $\mathrm{C}$, Jones JO, Kraman M, Wells RJ, Deonarine A, Chan DS, et al. Targeting CXCL12 from FAP-expressing carcinoma-associated fibroblasts synergizes with anti-PD-L1 immunotherapy in pancreatic cancer. Proc Natl Acad Sci U S A. 2013;110:20212-20217.

57. Kraman M, Bambrough PJ, Arnold JN, Roberts EW, Magiera L, Jones JO, et al. Suppression of antitumor immunity by stromal cells expressing fibroblast activation protein-alpha. Science. 2010;330:827-830.

58. Winograd R, Byrne KT, Evans RA, Odorizzi PM, Meyer AR, Bajor DL, et al. Induction of T-cell Immunity Overcomes Complete Resistance to PD-1 and CTLA-4 Blockade and Improves Survival in Pancreatic Carcinoma. Cancer Immunol Res. 2015;3:399-411.

59. Vogelstein B, Papadopoulos N, Velculescu VE, Zhou S, Diaz LA Jr, Kinzler KW. Cancer genome landscapes. Science. 2013;339:1546-1558.

60. Wan B, Nie H, Liu A, Feng G, He D, Xu R, et al. Aberrant regulation of synovial $\mathrm{T}$ cell activation by soluble costimulatory molecules in rheumatoid arthritis. J Immunol. 2006; $177: 8844-8850$.

61. Chen Y, Wang Q, Shi B, Xu P, Hu Z, Bai L, et al. Development of a sandwich ELISA for evaluating soluble PD-L1 (CD274) in human sera of different ages as well as supernatants of PDL1+ cell lines. Cytokine. 2011;56:231-238.

62. Frigola X, Inman BA, Krco CJ, Liu X, Harrington SM, Bulur PA, et al. Soluble B7-H1: differences in production between dendritic cells and T cells. Immunol Lett. 2012;142:78-82.

63. Song MY, Park SH, Nam HJ, Choi DH, Sung YC. Enhancement of vaccine-induced primary and memory 
CD8(+) T-cell responses by soluble PD-1. J Immunother. 2011;34:297-306.

64. Zhu X, Lang J. Soluble PD-1 and PD-L1: predictive and prognostic significance in cancer. Oncotarget. 2017;8:9767197682.

65. Wei W, Xu B, Wang Y, Wu C, Jiang J, Wu C. Prognostic significance of circulating soluble programmed death ligand-1 in patients with solid tumors: A meta-analysis. Medicine (Baltimore). 2018;97:e9617.

66. Zheng Z, Bu Z, Liu X, Zhang L, Li Z, Wu A, et al. Level of circulating PD-L1 expression in patients with advanced gastric cancer and its clinical implications. Chin J Cancer Res. 2014;26:104-111.

67. Bian B, Fanale D, Dusetti N, Roque J, Pastor S, Chretien AS, et al. Prognostic significance of circulating PD-1, PD-L1, panBTN3As, BTN3A1 and BTLA in patients with pancreatic adenocarcinoma. Oncoimmunology. 2019;8:e1561120.

68. Kruger S, Legenstein ML, Rösgen V, Haas M, Modest DP, Westphalen CB, et al. Serum levels of soluble programmed death protein 1 (sPD-1) and soluble programmed death ligand 1 (sPD-L1) in advanced pancreatic cancer. Oncoimmunology. 2017;6:e1310358.

69. Park H, Bang JH, Nam AR, Eun Park J, Hua Jin M, Bang YJ, et al. Prognostic implications of soluble programmed death-ligand 1 and its dynamics during chemotherapy in unresectable pancreatic cancer. Sci Rep. 2019;9:11131.

70. Elhag OA, Hu XJ, Wen-Ying Z, Li X, Yuan YZ, Deng $\mathrm{LF}$, et al. Reconstructed adeno-associated virus with the extracellular domain of murine PD-1 induces antitumor immunity. Asian Pac J Cancer Prev. 2012;13:4031-4036.

71. Kim ST, Klempner SJ, Park SH, Park JO, Park YS, Lim $\mathrm{HY}$, et al. Correlating programmed death ligand 1 (PD-L1) expression, mismatch repair deficiency, and outcomes across tumor types: implications for immunotherapy. Oncotarget. 2017;8:77415-77423

72. Tempero MA, Malafa MP, Al-Hawary M, Behrman SW, Benson AB, Cardin DB, et al. Pancreatic Adenocarcinoma, Version 2.2021, NCCN Clinical Practice Guidelines in Oncology. J Natl Compr Canc Netw. 2021;19:439-457.

73. Marabelle A, Le DT, Ascierto PA, Di Giacomo AM, De JesusAcosta A, Delord JP, et al. Efficacy of Pembrolizumab in Patients With Noncolorectal High Microsatellite Instability/ Mismatch Repair-Deficient Cancer: Results From the Phase II KEYNOTE-158 Study. J Clin Oncol. 2020;38:1-10.

74. Diaz LA, Marabelle A, Delord JP, Shapira-Frommer R, Geva $\mathrm{R}$, Peled N, et al. Pembrolizumab therapy for microsatellite instability high (MSI-H) colorectal cancer (CRC) and non-CRC. Journal of Clinical Oncology. 2017;35(15 suppl):3071.

75. Hu ZI, Shia J, Stadler ZK, Varghese AM, Capanu M, Salo-Mullen E, et al. Evaluating Mismatch Repair Deficiency in Pancreatic Adenocarcinoma: Challenges and Recommendations. Clin Cancer Res. 2018;24:1326-1336.

76. Eatrides JM, Diffalha SA, Kim RD, Springett GM, Mahipal
A. Microsatellite instability in pancreatic cancer. J Clin Oncol. 2016;34(Suppl. 15):e15753.

77. Samstein RM, Lee CH, Shoushtari AN, Hellmann MD, Shen R, Janjigian YY, et al. Tumor mutational load predicts survival after immunotherapy across multiple cancer types. Nat Genet. 2019;51:202-206.

78. Zhao P, Li L, Jiang X, Li Q. Mismatch repair deficiency/ microsatellite instability-high as a predictor for antiPD-1/PD-L1 immunotherapy efficacy. J Hematol Oncol. 2019;12:54.

79. Chalmers ZR, Connelly CF, Fabrizio D, Gay L, Ali SM, Ennis R, et al. Analysis of 100,000 human cancer genomes reveals the landscape of tumor mutational burden. Genome Med. 2017;9:34.

80. Yarchoan M, Albacker LA, Hopkins AC, Montesion M, Murugesan K, Vithayathil TT, et al. PD-L1 expression and tumor mutational burden are independent biomarkers in most cancers. JCI Insight. 2019;4:e126908.

81. Welcsh PL, King MC. BRCA1 and BRCA2 and the genetics of breast and ovarian cancer. Hum Mol Genet. 2001;10:705713.

82. Thompson D, Easton DF; Breast Cancer Linkage Consortium. Cancer Incidence in BRCA1 mutation carriers. J Natl Cancer Inst. 2002;94:1358-1365.

83. Golan T, Hammel P, Reni M, Van Cutsem E, Macarulla T, Hall MJ, et al. Maintenance Olaparib for Germline BRCAMutated Metastatic Pancreatic Cancer. N Engl J Med. 2019;381:317-327.

84. Cheung PF, Lutz M, Siveke JT. Immunotherapy and Combination Strategies in Pancreatic Cancer: Current Status and Emerging Trends. Oncol Res Treat. 2018;41:286-290.

85. Cortes E, Lachowski D, Rice A, Thorpe SD, Robinson B, Yeldag $\mathrm{G}$, et al. Tamoxifen mechanically deactivates hepatic stellate cells via the $\mathrm{G}$ protein-coupled estrogen receptor. Oncogene. 2019;38:2910-2922.

86. Wei MY, Shi S, Liang C, Meng QC, Hua J, Zhang YY, et al. The microbiota and microbiome in pancreatic cancer: more influential than expected. Mol Cancer. 2019;18:97.

87. Manzat-Saplacan RM, Mircea PA, Balacescu L, Chira RI, Berindan-Neagoe I, Balacescu O. Can we change our microbiome to prevent colorectal cancer development? Acta Oncol. 2015;54:1085-1095.

88. Vétizou M, Pitt JM, Daillère R, Lepage P, Waldschmitt $\mathrm{N}$, Flament $\mathrm{C}$, et al. Anticancer immunotherapy by CTLA-4 blockade relies on the gut microbiota. Science. 2015;350:1079-1084.

89. Sivan A, Corrales L, Hubert N, Williams JB, AquinoMichaels K, Earley ZM, et al. Commensal Bifidobacterium promotes antitumor immunity and facilitates anti-PD-L1 efficacy. Science. 2015;350:1084-1089.

90. Kumar V, Chaudhary N, Garg M, Floudas CS, Soni P, Chandra AB. Current Diagnosis and Management of Immune Related Adverse Events (irAEs) Induced by Immune Checkpoint Inhibitor Therapy. Front Pharmacol. 2017;8:49. 